\title{
The Antifungal Properties of Peppermint and Thyme Essential Oils Misted in Broiler Houses
}

http://dx.doi.org/10.1590/1806-9061-2016-0266

-Author(s)

\section{Witkowska D \\ Sowińska J' \\ Żebrowska JPI \\ Mituniewicz E'}

Department of Animal and Environmental Hygiene, Faculty of Animal Bioengineering, University of Warmia and Mazury, Olsztyn, Poland

\section{ABSTRACT}

This study aimed at evaluating if essential oils misted in broiler houses reduce environmental fungi counts. The investigation was conducted in three experimental rooms, where broiler chickens were reared between 1 to $42 \mathrm{~d}$ of age. Every three days, the rooms were fogged with pure water (control) or with aqueous solutions of peppermint or thyme oils. On the next day, fogging samples from the air, flat surfaces, and litter were collected and quantitatively and qualitatively analysed for fungal contamination. The treatment with essential oils showed promising results. In the room fogged with thyme oil, aerial fungi growth was not as evident as in the control room, and presented the lowest average fungi count. Thyme oil was also the most effective in reducing fungi colonization on drinker surfaces and litter. The use of peppermint oil also reduced the population of air, wall, surface and litter fungi, although some exceptions were noted. Aspergillus, Penicillium, Fusarium and Saccharomyces genera were identified most frequently. The effect of essential oils was noticeable in the last two weeks, when the counts of Aspergillus sp. were 75\% (thyme oil) and 46\% (peppermint oil) lower in comparison with the control group. The results show that fogging broiler houses with essential oils may be an effective prevention method against fungal aerosol in broiler houses. However, further investigations to determine the synergistic effect of different oils and their compounds, and the best possible doses and methods of application in the field are needed.

\section{INTRODUCTION}

The specific microclimate inside poultry houses contributes to an above-average concentration of biological contamination (Seedorf et al., 1998; Vučemilo et al., 2007; Witkowska \& Sowińska, 2013). Factors, such as the high temperature and humidity of air and litter, as well as the high number of large birds, contribute for the formation of fungal aerosol (Russel \& Paluchowska-Święcka, 2008; Witkowska et al., 2010). The results of some studies demonstrate that the level of aerial fungi in broiler houses ranges between 3.0 and $6.6 \log _{10}$ CFU/ $\mathrm{m}^{3}$, depending on housing systems, litter quality and moisture, bird age and activity, and season of the year (Seedorf et al., 1998; Gigli et al., 2005; Vučemilo et al., 2007; Mituniewicz et al., 2008; Lonc \& Plewa, 2010; Witkowska et al., 2010; Wójcik et al., 2010; Okiki \& Ogbimi, 2011). The concentration of total fungi in the litter is considerably larger in comparison with air. A study carried out during a broiler chicken production cycle showed a range between 6.4 and $8.0 \log _{10}$ $\mathrm{CFU} / \mathrm{m}^{3}$ (Witkowska et al., 2010). According to many authors, broiler houses are particularly infested by fungi of the genera Penicillium, Aspergillus, and Fusarium (Gigli et al., 2005; Vučemilo et al., 2007; 
Mituniewicz et al., 2008; Nichita \& Tirziu, 2008; Witkowska et al., 2010; Wójcik et al., 2010; Okiki \& Ogbimi, 2011), which are the main fungi-producing pathogenic mycotoxins (Krnjaja et al., 2008; Wang et al., 2008; Okiki \& Ogbimi, 2011). Other toxigenic fungi species, e.g. Alternaria, Cladosporium, Trichoderma, Rhizophus, Stachybotrys (Karwowska, 2005; Krnjaja et al., 2008; Okiki \& Ogbimi, 2011) have also been identified in poultry houses (Mituniewicz et al., 2008; Wang et al., 2008; Lonc \& Plewa, 2010; Wójcik et al., 2010; Okiki \& Ogbimi, 2011; Sowiak et. al., 2012).

The pathogenic effects of those fungi, as well as of other molds and yeasts (Trichosporon sp., Mucor sp., Geotrichum sp., Chaetomium sp., Scopulariopsis sp., Candida albicans, C. tropicalis, Cryptococcus neoformans, Rhodotorula mucilaginesa, etc.), are intensified when pollutants are found in high concentrations, and when chickens are exposed to the combined effects of other immunosuppressive factors (Sawale et al., 2012; Dhama et al., 2013). Large quantities of the fungi spores, particularly inhalable particles with an aerodynamic diameter smaller than $5 \mu \mathrm{m}$, pose a significant threat to chickens and farm personnel (Nichita \& Tirziu, 2008; Sowiak et al., 2012). The most frequent poultry fungal infections, such as aspergillosis and candidiosis, are caused by fungi which are commonly found in the environment of birds (Dhama et al., 2013). According to Arné et al. (2011), there are no treatments for infected poultry, and therefore, the only effective way to protect chickens against mycoses is prevention.

Misting with water is one of the methods used to reduce dust and fungal spores in the air of poultry buildings. Mist-fog systems are increasingly being installed in poultry buildings to administer inhaled vaccines or drugs, to reduce summertime heat stress, and to improve sanitation (Shanmugavelu et al., 2000; Vermeulen et al., 2002). The studies of Witkowska and Sowińska (2013) indicate that misting poultry houses with aqueous solutions of peppermint and thyme essential oils offers promising prospects for bacterial reduction in the birds' environment. The positive effect of essential oils (pine and eucalyptus) in aerial bacteria reduction in poultry houses was observed by Bakutis et al. (2011). Furthermore, these authors demonstrate that the essential oils were also effective against airborne fungi. Inouye et al. (2003) indicates that the in-vitro growth of fungi was inhibited by lower agar concentration by gaseous contact than by solution contact.
Further research on the antifungal effectiveness of essential oils was carried out in-vitro. These studies have demonstrated that essential oils eliminate fungi, including yeasts (Candida albicans), filamentous fungi (Aspergillus flavus, A. fumigatus, A. niger, Penicillium chrysogenum, Trichoderma viride, Mucor hiemalis), as well as dermatophytes (Trichophyton mentagrophytes, T. rubrum, Epidermophyton floccosum, Microsporum canis and M. gypseum), as shown by Hammer et al. (1999), Inouye et al. (2003), Azaz et al. (2004), Tampieri et al. (2005), Chuang et al. (2007), Kędzia \& Hołderna-Kędzia (2007), Yang \& Clausen (2007), Omran \& Esmailzadeh (2009), and Pinto et al. (2009).

Tampieri et al. (2005) evaluated the in-vitro inhibiting activity of 16 essential oils (EO) and their main constituents against a Candida albicans strain, and found that Mentha piperita EO showed high inhibitory activity even after seven days. The inhibition of the growth of fungal pathogens may be due to major components, such as menthone, menthol, and menthofuran. Furthermore, it is possible that other minor components may act synergistically (Moghaddam et al., 2013). The results of Iscan et al. (2002) showed that menthone was less active than menthol against $C$. albicans. In a study by Moghtader (2013), peppermint oil at 1 and 0.5 dilutions exhibited stronger antifungal effect than gentamycin or synthetic menthol.

According to Klarić et al. (2007), thyme essential oil possesses a wide spectrum of fungicidal activity. Omran and Esmailzadeh (2009), who compared different EOs and antifungal drugs, reported that thyme essential oil presented the strongest inhibitory effect against different pathogenic Candida species among the tested EOs, and the inhibitory zone around the colony obtained with amphotericin B by was smaller than that observed with thyme essential oil. Katooli et al. (2012) showed that thyme essential oil presented stronger antifungal activity in comparison with eucalyptus oil, and thyme $\mathrm{EO}$ at 50, 75 and 100\% concentrations completely inhibited mycelial growth. The investigation conducted by Riccioni and Orzali (2011) also showed that $T$. vulgaris oil is one of the most potent agents against fungi. Rusenova and Parvanov (2009) also determined thyme oil activity as one of the most potent against bacteria and yeasts of veterinary importance. Klarić et al. (2007) demonstrated that the vaporous phase of thyme oil exhibited long-lasting suppressive activity on molds from damp dwellings.

The aim of this study was to determine if peppermint and thyme essential oils misted in broiler houses reduce the count of environmental fungi. 


\section{MATERIALS AND METHODS}

\section{Chicken housing}

The experiment was conducted from April to May in three separate rooms, where 360 broiler chickens (120 in each room) were reared from 1 to 42 days. The population density of each room was 13 birds per 1 $\mathrm{m}^{2}$, and was equivalent $22 \mathrm{~kg} / \mathrm{m}^{2}$ before slaughtering. Suitable broiler chicken rearing rooms with an area of $9.25 \mathrm{~m}^{2}$ were identically equipped and managed. The climate was controlled by mechanical forced-air ventilation and a lighting system. Unsexed Ross 308 chickens were reared on floors covered with a straw litter, according to standard requirements. Birds were fed a complete commercial diet (Rolpol, Uścikowo, Poland) ad libitum.

\section{Climate control}

The dry bulb temperature $\left({ }^{\circ} \mathrm{C}\right)$ and relative humidity (\%) were recorded continuously every 30 minutes during the whole experiment. An thermo-hygrometer (model LB 520, Lab-El, Poland) used for climate control was calibrated according to the PN-EN ISO/IEC 17025:2005 standard, LAB-EL, Poland).

\section{Essential oil dosing}

Before placement, and every third day of the whole rearing period, the experimental rooms were fogged with $0.5 \mathrm{~L}$ aqueous solutions of $100 \%$ natural peppermint oil from Mentha piperita and thyme oil from Thymus vulgaris L. (ETJA Corp., Elbląg, Poland). The concentration of oils in water from day 1 to day 14 was 1:500, and it was increased to 1:250 from day 15 to day 42. The control room was misted with pure water at the same dose as in experimental rooms. Aerosol particles under $50 \mu \mathrm{m}$ were generated by a Mgła-E fogger (Poltech Corp., Warsaw, Poland).

\section{Fungi sampling}

Onedafterfogging(every $3 \mathrm{~d}$ )sampleswerecollected from the air, litter, walls and drinkers for quantitative and qualitative analyses of fungi. Air samples were collected on Petri dishes $(90 \mathrm{~mm}$ ) with commercial Sabouraud glucose agar with chloramphenicol (Sigma-Aldrich Corp., Poznań, Poland). An air IDEAL 3P sampler (bioMérieux Corp., Craponne, France) operated on the Andersen impaction principle (air intake $100 \mathrm{~L} / \mathrm{min}$, impact speed of less than $20 \mathrm{~m} / \mathrm{s}$, air volume 5-10 L) was used for aerial fungi sampling. The samples were collected at five points in each room: on two sides along two diagonals, and in the center. After about one week incubation at $25^{\circ} \mathrm{C}$, the number of fungi was determined using an automated colony counter (Schuett colonyQuant, Schuett-Biotec Corp., Göttingen, Germany). Total fungi count was expressed in colony forming units (CFU) per cubic meter $\left(\mathrm{m}^{3}\right)$ of air after correction, according to Feller's conversion formula. Based on morphological criteria (Litvinov, 1967; Piontek, 1999), the genera of predominating aerial fungi were identified using an MN-800 microscope (OPTA-TECH Corp., Warsaw, Poland).

Triple smear samples at 2 points on walls and drinkers were collected in every analytical series according to the PN-ISO 18593:2005 standard (2005). Samples from the flat surfaces of walls were obtained using sterile templates measuring $10 \mathrm{~cm} \times 10 \mathrm{~cm}$ and sterile cotton swabs moistened with sterile peptone saline (Merck Corp.). Swab samples from drinkers were taken from the same area in each measurement. Swabs were immersed in peptone saline solution and shaken. Litter samples were collected using a sterile spatula from five points in each experimental room, and one gram of bulk samples was diluted at 1:9 (wt/vol) in sterile peptone saline. Ten sequential 1:9 ( $\mathrm{vol} / \mathrm{vol})$ dilutions were made from all walls, drinkers and litter samples. One $\mathrm{mL}$ of each dilution was inoculated in Petri dishes with Sabouraud glucose agar with chloramphenicol in duplicate (Sigma-Aldrich Corp., Poznań, Poland). PNISO 21527-1:2009 and Sigma standards were used for fungus assays.

\section{Statistical Analysis}

The obtained fungus counts were $\log _{10}$ transformed before statistical analysis. After logarithm transformation, the data were normally distributed, as confirmed by the Kolmogorov-Smirnov test. All variables were subjected to one-way analysis of variance (ANOVA), and the differences among means were determined by Duncan's multiple range test. Statistica 10 software (StatSoft Inc., Tulsa, OK) was used for statistical analysis.

Table 1 presents the total fungi counts before stocking. The means ( \pm standard deviations) of the fungi and the differences among groups are shown in Tables 2-5. The percentage of genera of aerial fungi in weeks 1-2, 3-4, and 5-6 was calculated using Microsoft Excel software (Microsoft Corp.), and the results are presented in Figures 3 to 5 . The average daily dry bulb temperature $\left({ }^{\circ} \mathrm{C}\right)$ and relative humidity (\%) inside and outside the experimental rooms are shown in Figures 1 and 2. 


\section{RESULTS}

The average daily temperature outside the broiler houses fluctuated noticeably throughout the experiment from $1-2^{\circ} \mathrm{C}$ at the beginning of the cycle to $20-23^{\circ} \mathrm{C}$ in the last two weeks (Figure 1). The average daily temperatures were comparable between experimental rooms, and their values were not statistically different. Mean daily temperature during the first days of rearing ranged between $26-28^{\circ} \mathrm{C}$. Temperature values decreased on the following days, and fluctuated from $23^{\circ} \mathrm{C}$ to $27^{\circ} \mathrm{C}$. In the last week, air temperature in experimental rooms fell to $18-20^{\circ} \mathrm{C}$, and in the last two days, it increased again to $24-26^{\circ} \mathrm{C}$. The outdoor relative humidity during the whole experiment ranged from $43 \%$ to $97 \%$ (Figure 2). Indoor air humidity in the first two weeks was $21-40 \%$. After day 14 , the mean daily relative humidity increased to $45-69 \%$. However, on selected days, air humidity inside broiler houses fell below $40 \%$. There were no relative humidity statistical differences among experimental rooms.

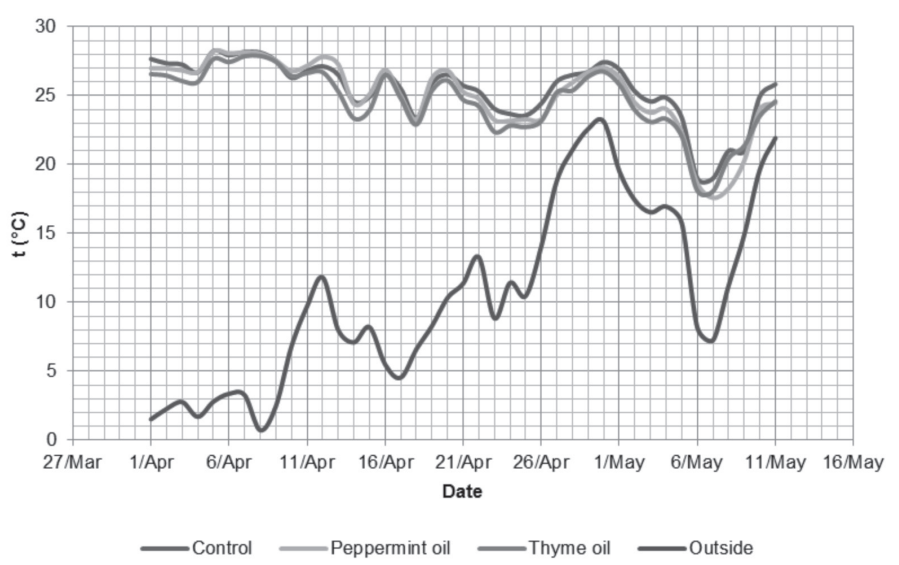

Figure 1 - Daily temperature $\left({ }^{\circ} \mathrm{C}\right)$ measured inside and outside the broiler rooms. Averages of continuous (every 30 minutes) measurements.

The results of mycological studies show that, after room preparation for placement, the aerial contamination by fungi ranged between 2.6 and 2.8 $\log _{10} \mathrm{CFU} / \mathrm{m}^{3}$ (Table 1). One $\mathrm{d}$ after essential-oil fogging, the concentration of air fungi in the control and thyme oil groups was similar, and oscillated around 2.5 - 2.9 $\log _{10} \mathrm{CFU} / \mathrm{m}^{3}$, whereas the fungal contamination of the air in the room fogged with peppermint oil decreased below $2.0 \log _{10} \mathrm{CFU} / \mathrm{m}^{3}$. On the wall surfaces, the count of fungi before and after the essential oil treatment was not identified, or their count was lower than $0.6 \log _{10} \mathrm{CFU} / \mathrm{cm}^{2}$. The contamination of drinkers was determined at 1.0-1.4 $\log _{10}$ before essential oil treatment, and after the fogging the count of fungi in each room was around $0.5 \log _{10}$ lower. The average count of litter fungi was similar in each room before and after essential oil use, and oscillated close to 3 $\log _{10}$.

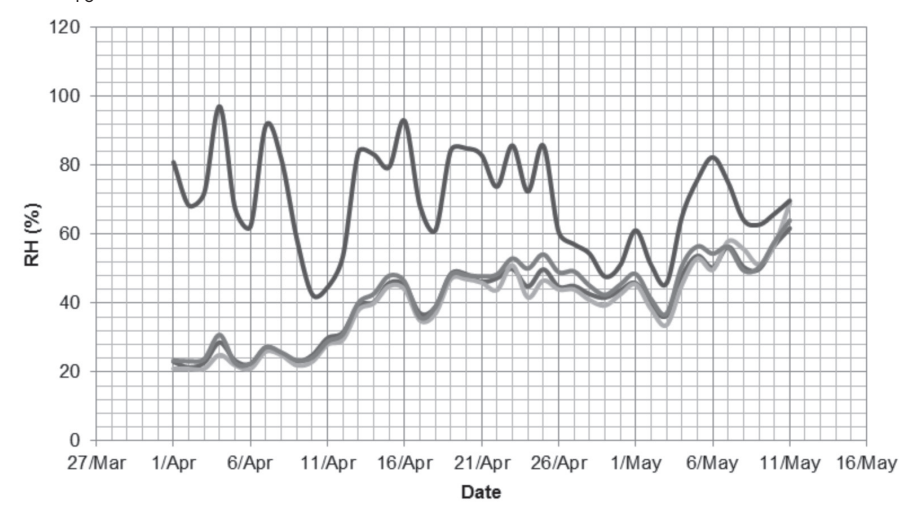

Control - Peppermint oil —Thyme oil —outside

Figure 2 - Daily air relative humidity (\%) measured inside and outside the broiler rooms. Averages of continuous (every 30 minutes) measurements.

The total count of aerial fungi during rearing (Table 2) was statistically different in each group. The average contamination throughout the entire growth cycle was around $0.5 \log _{10} \mathrm{CFU} / \mathrm{m}^{3}$ lower in the room fogged with thyme oil in comparison with the control group $(p=0.001)$. The level of aerial fungi in the room treated with peppermint oil was lower than that in the control room, and higher than in the room where thyme oil was used (around $0.23 \log _{10}$ ). The results of mycological studies in particular weeks of chicken rearing confirm that the air in the room fogged with thyme oil was the cleanest, and were statistically different in the first, fourth and fifth weeks ( $p=0.016 ; p=0.001 ; p=0.009$, respectively) compared with the other rooms. In the case of peppermint oil, air fungi were also reduced, with a single exception in the fourth week, where higher contamination than in the control room was observed $(p=0.001)$. In the control room, the mean fungus count value in the first week was $3.0 \log _{10}$ CFU/

Table 1 - Total counts of fungi $\left(\log _{10}\right.$ CFU) in the air, on the walls and drinkers, and in the litter before chick placement.

\begin{tabular}{|c|c|c|c|c|c|c|}
\hline \multirow{2}{*}{ Places } & \multicolumn{3}{|c|}{ Before essential oil treatment } & \multicolumn{3}{|c|}{ After essential oil treatment } \\
\hline & Control & Peppermint oil & Thyme oil & Control & Peppermint oil & Thyme oil \\
\hline Air $\left(m^{3}\right)$ & 2.66 & 2.76 & 2.55 & 2.93 & 1.98 & 2.49 \\
\hline Walls $\left(100 \mathrm{~cm}^{2}\right)$ & 0.00 & 0.00 & 0.60 & 0.48 & 0.00 & 0.00 \\
\hline Drinkers (unsized) & 1.42 & 0.98 & 1.08 & 0.95 & 0.00 & 0.47 \\
\hline Litter $(\mathrm{g})$ & 2.66 & 2.15 & 3.67 & 2.93 & 2.59 & 2.99 \\
\hline
\end{tabular}


$\mathrm{m}^{3}$, and the contamination increased gradually in the next weeks to $3.9 \log _{10} \mathrm{CFU} / \mathrm{m}^{3}$ in the last week. In the experimental rooms, the count of fungi was lower $(p=0.016)$ at the beginning of rearing and did not exceed $2.4 \log _{10} \mathrm{CFU} / \mathrm{m}^{3}$. The growing trend of aerial contamination in the next weeks, especially in room where thyme oil was used, was not as visible as in the control room.

Table 2 - Total count of aerial fungi $\left(\log _{10} \mathrm{CFU} / \mathrm{m}^{3}\right)$ during the rearing period (mean \pm standard deviation)

\begin{tabular}{lcccc}
\hline Week & $\mathrm{n}$ & Control & Peppermint oil & Thyme oil \\
\hline 1 & 10 & $3.00^{\mathrm{a}} \pm 0.45$ & $2.43^{\mathrm{b}} \pm 0.34$ & $2.38^{\mathrm{b}} \pm 0.32$ \\
2 & 10 & $3.20 \pm 0.33$ & $3.03 \pm 0.66$ & $2.91 \pm 0.33$ \\
3 & 10 & $3.57 \pm 0.33$ & $3.45 \pm 0.23$ & $3.27 \pm 0.56$ \\
4 & 10 & $3.51^{\mathrm{B}} \pm 0.10$ & $3.84^{\mathrm{A}} \pm 0.09$ & $3.10^{\mathrm{C}} \pm 0.10$ \\
5 & 10 & $3.68^{\mathrm{Aa}} \pm 0.58$ & $3.10^{\mathrm{b}} \pm 0.13$ & $2.99^{\mathrm{B}} \pm 0.28$ \\
6 & 10 & $3.90 \pm 0.77$ & $3.65 \pm 0.10$ & $3.51 \pm 0.16$ \\
\hline
\end{tabular}

Mean values represent the averages of each measurement (every 3 days) - from wk 1 to 6.

A to $\mathrm{C}$ Means within a row with different uppercase superscripts differ $(p<0.01)$.

a to bMeans within a row with different lowercase superscripts differ $(p<0.05)$.

Wall contamination (Table 3) in each group during the entire rearing cycle was below $1.0 \log _{10} \mathrm{CFU} / \mathrm{cm}^{2}$. The mean count of wall fungi throughout the entire experimental period was highest in the control room (0.52 $\log _{10}\left(\mathrm{FU} / \mathrm{cm}^{2}\right)$, and was statistically different from the room fogged with thyme EO $(p=0.001)$. The presence of wall fungi in particular weeks of chicken growing was not determined in the room fogged with peppermint oil. In the room treated with thyme EO, the contamination in the subsequent weeks was lower in comparison with the control room, and in the last week fungus count was statistically reduced in more than $0.5 \log _{10} \mathrm{CFU} / \mathrm{cm}^{2}(\mathrm{p}=0.022)$. In the third week, similarly to the peppermint group, wall contamination in this room was not detected.

Table 3 - Total count of fungi on the walls ( $\log _{10}$ CFU/100 $\mathrm{cm}^{2}$ ) during the rearing period (mean \pm standard deviation)

\begin{tabular}{lllll}
\hline Week & $\mathrm{n}$ & Control & Peppermint oil & Thyme oil \\
\hline 1 & 12 & $0.00 \pm 0.00$ & $0.00 \pm 0.00$ & $0.00 \pm 0.00$ \\
2 & 12 & $0.69 \pm 0.35$ & $0.00 \pm 0.00$ & $0.39 \pm 0.27$ \\
3 & 12 & $0.60 \pm 0.37$ & $0.00 \pm 0.00$ & $0.00 \pm 0.00$ \\
4 & 12 & $0.48 \pm 0.21$ & $0.00 \pm 0.00$ & $0.15 \pm 0.10$ \\
5 & 12 & $0.50 \pm 0.28$ & $0.00 \pm 0.00$ & $0.18 \pm 0.09$ \\
6 & 12 & $0.84^{\mathrm{a}} \pm 0.33$ & $0.00^{\mathrm{b}} \pm 0.00$ & $0.30^{\mathrm{ab}} \pm 0.07$ \\
\hline
\end{tabular}

Mean values represent the averages of each measurement (every 3 days) - from wk 1 to 6.

a to bMeans within a row with different superscripts differ $(p<0.05)$.

The fungal contamination of drinkers in the room where thyme oil was used was about $0.5 \log _{10}$ lower $(p=0.004)$ in comparison with the control room (Table
4). The count of fungi in the drinkers of the room treated with peppermint oil was intermediate, and was not statistically different from the other rooms. The mycological analysis of the drinker surfaces in particular weeks show a similar tendency. The lowest drinker contamination was observed in the room fogged with thyme oil from the third week to the end of rearing, with a reduction of the fungi population of up to $50 \%$ (week 3 and 4 ) relative to the control group ( $p=0.013$ and $p=0.008$, respectively). In the room where peppermint oil was used, considerable variations in drinker contamination among weeks were detected. In week 4, fungal count in the drinkers in this room was the highest $(p=0.004)$, while in weeks 3 and 6 , it was statistically lower than in the control room (Table 4).

Table 4 - Total count of fungi on the drinkers $\left(\log _{10}\right.$ CFU) during the rearing period (mean \pm standard deviation)

\begin{tabular}{lllll}
\hline Week & $\mathrm{n}$ & Control & Peppermint oil & Thyme oil \\
\hline 1 & 12 & $1.21 \pm 0.06$ & $1.04 \pm 0.21$ & $1.14 \pm 0.26$ \\
2 & 12 & $1.02 \pm 0.08$ & $1.74 \pm 0.38$ & $0.98 \pm 0.29$ \\
3 & 12 & $2.30^{\mathrm{a}} \pm 0.21$ & $1.35^{\mathrm{b}} \pm 0.29$ & $1.14^{\mathrm{b}} \pm 0.14$ \\
4 & 12 & $1.81^{\mathrm{B}} \pm 0.01$ & $1.97^{\mathrm{A}} \pm 0.02$ & $0.93^{\mathrm{C}} \pm 0.03$ \\
5 & 12 & $1.78^{\mathrm{A}} \pm 0.13$ & $1.48^{\mathrm{a}} \pm 0.21$ & $1.14^{\mathrm{Bb}} \pm 0.08$ \\
6 & 12 & $1.75^{\mathrm{a}} \pm 0.20$ & $1.33^{\mathrm{b}} \pm 0.14$ & $1.26^{\mathrm{b}} \pm 0.02$ \\
\hline
\end{tabular}

Mean values represent the averages of each measurement (every 3 days) - from wk 1 to 6 .

A to CMeans within a row with different uppercase superscripts differ $(p<0.01)$.

a to bMeans within a row with different lowercase superscripts differ $(p<0.05)$.

Litter mycological contamination ranged from 3.8 $\log _{10}$ CFU/g at the beginning of the rearing period to $6.0 \log _{10}$ CFU/g in the last week in the control room. The size of the fungi population in experimental rooms was lower (it did not exceed $5.5 \log _{10}$ ), but not statistically different. The lowest average contamination during the entire rearing period (below $5.0 \log _{10}$ ) was detected in the room fogged with thyme oil. In this room, fungal count did not exceed 5 logarithms in most weeks, whereas in the control room (except for the first week) fungal count exceeded $5.3 \log _{10} \mathrm{CFU} / \mathrm{g}$.

The percentage analysis of fungus genera (Figures 3-5) indicates that the most frequent fungi in all rooms were Aspergillus, Penicillium, Fusarium, and Saccharomyces. In the first two weeks (Figure 3), Aspergillus and Penicillium species were at the highest level, and in the next two periods (Figure 4), a visible drop in the percentage of Penicillium was noted. The opposite tendency was observed for Saccharomyces. The count of this genus noticeably increased in the last two weeks in all rooms (Figure 5). It should be noted that the count of yeasts in the first four weeks 
was the highest in the control room compared with the experimental rooms. However, in the last period, despite the rapid rise, the level of these genera in the control room was the lowest. Opposite to the experimental rooms, the count of Aspergillus sp. in the control group in the last two weeks did not significantly decrease, and was similar to yeast concentration. On the other hand, in the experimental rooms at the end of rearing, Saccharomyces represented most of the fungal population.

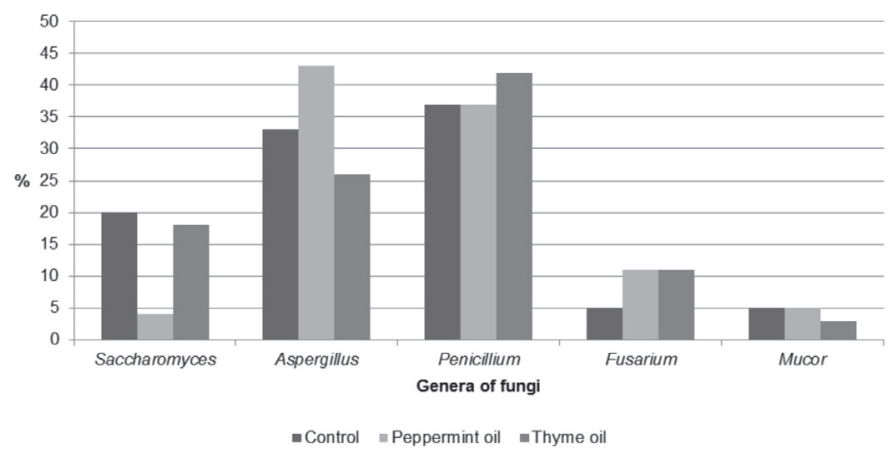

Figure 3 - Percentage of genera of aerial fungi in weeks 1-2. Averages of two measurements per week.

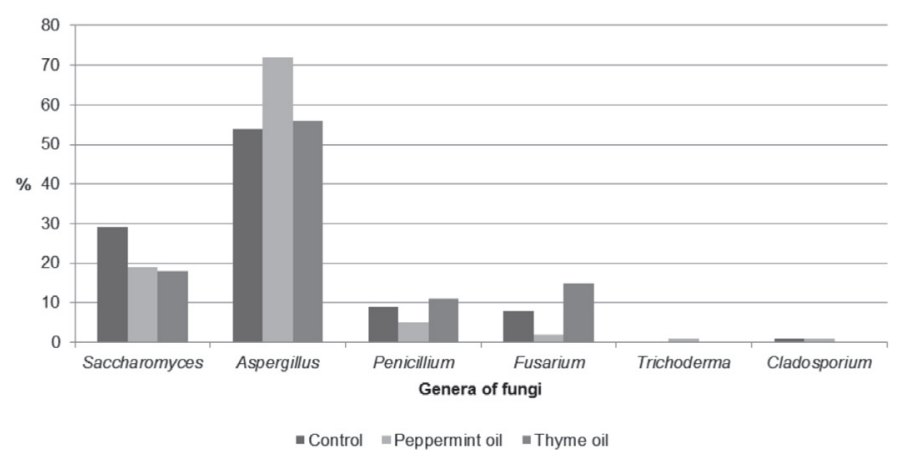

Figure 4 - Percentage of genera of aerial fungi in weeks 3-4. Averages of two measurements per week.

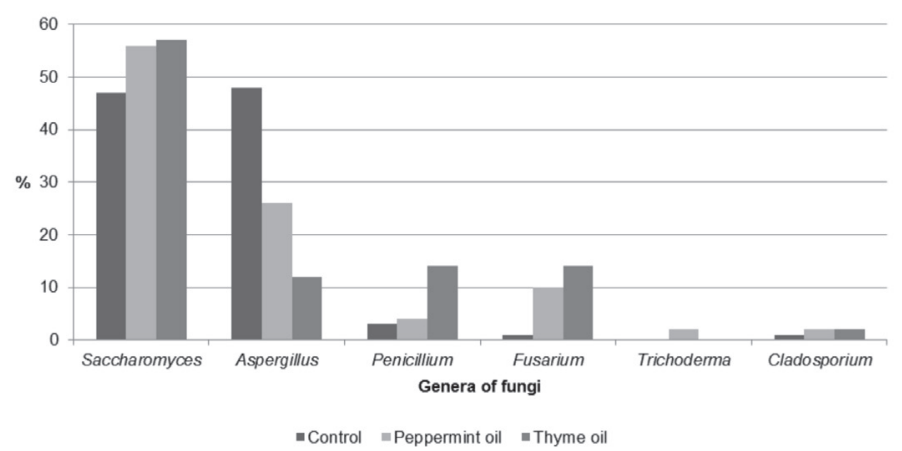

Figure 5 - Percentage of genera of aerial fungi in weeks 5-6. Averages of two measurements per week.

\section{DISCUSSION}

The climatic parameters of experimental broiler houses complied with the provisions of European Union Directive 2007/43/EC (EU Council, 2007). The inside air temperature was not higher than the outside temperature, and ranged between 28 and $18^{\circ} \mathrm{C}$, depending on broiler age and climate parameters. The air relative humidity increased from $21 \%$ to $69 \%$ during the production cycle, and did not exceed $70 \%$ in compliance with that regulation. However, it should be noted that the temperature and relative humidity values inside the broiler rooms were fairly changeable due to the temperate climatic meteorological conditions typical of spring. The rapid rise in air temperature and the relatively high moisture in spring, in particular, support the growth of fungi outside the poultry house, and therefore, the external environment may also be a potential source of fungi found inside the house (Nardoni et al., 2005; Russel \& Paluchowska-Święcka, 2008; Witkowska et al., 2012).

This study demonstrates that the presence of fungi in broiler rooms was observed even after cleaning and disinfection before placement (Table 1). The airborne fungi concentration at the beginning of the production cycle approached $3 \log _{10} \mathrm{CFU} / \mathrm{m}^{3}$, which is considered a risk for respiratory disease in animals (Dutkiewicz et al., 1994). Proper hygienic standards are required for adequate animal welfare, and methods for the sanitation of poultry environments are described by different researchers (Tymczyna et al., 2007; Witkowska et al., 2007; Mituniewicz et al., 2008; Bakutis et. al., 2011). The treatment with essential oils before chick placement was effective, despite the exception observed in the case of litter in the room fogged with peppermint oil. It should be underlined that the litter, especially that obtained and stored in unfavorable climatic conditions, can be a major source of fungi in poultry houses, and that litter fungal contamination is not homogenous.

The count of air fungi in the control group (Table 2) tended to increase during the entire rearing period, and achieved almost $4.0 \log _{10} \mathrm{CFU} / \mathrm{m}^{3}$ in the last week. On the other hand, in the room treated with thyme oil, this increasing trend was not as evident, and the highest average value obtained in this room did not exceed 3.5 $\log _{10} \mathrm{CFU} / \mathrm{m}^{3}$ and was the lowest compared with the other treatments. Thyme oil was also the most effective in reducing fungal colonization of drinker surfaces and of the litter (Table 4 and 5). The use of peppermint oil also reduced the population of air, surface, and litter fungi, except for week 4, when air and drinker fungal counts were the highest relative to the other rooms. On the other hand, the contamination of wall surfaces (Table 3) in the room fogged with peppermint oil was not detected neither in week 4 or any other week. 
Table 5 - Total count of fungi in the litter $\left(\log _{10}\right.$ CFU/g) during the rearing period (mean \pm standard deviation)

\begin{tabular}{lllll}
\hline Week & $\mathrm{n}$ & Control & Peppermint oil & Thyme oil \\
\hline 1 & 10 & $3.80 \pm 1.13$ & $4.95 \pm 1.34$ & $4.18 \pm 1.41$ \\
2 & 10 & $5.54 \pm 0.30$ & $4.59 \pm 0.89$ & $5.58 \pm 0.51$ \\
3 & 10 & $5.32 \pm 0.38$ & $5.02 \pm 0.11$ & $4.87 \pm 0.55$ \\
4 & 10 & $5.57 \pm 0.01$ & $5.55 \pm 1.03$ & $4.05 \pm 0.49$ \\
5 & 10 & $5.29 \pm 0.56$ & $5.12 \pm 0.46$ & $4.80 \pm 0.39$ \\
6 & 10 & $6.02 \pm 0.82$ & $5.05 \pm 1.04$ & $5.51 \pm 0.60$ \\
\hline
\end{tabular}

Mean values represent the averages of each measurement (every 3 days) - from wk 1 to 6 .

Consistent with other investigations (Karwowska, 2005; Witkowska et al., 2010; Wójcik et al., 2010), Aspergillus, Penicillium, and Fusarium genera were the most frequently identified in our study. Saccharomyces was also common, especially in the last period (weeks 5 and 6). In the first two weeks of the rearing cycle, the differentiation of fungi in each room was more evident (Figure 3). In the next two weeks, Penicillium sp. count was reduced, whereas Aspergillus sp. count was the highest. The effect of essential oils was noticeable in the last two weeks, when Aspergillus sp. counts were $75 \%$ (thyme oil) and $46 \%$ (peppermint oil) lower in comparison with the control group. Similar to other studies (Witkowska et al., 2010), the end of rearing was also characterized by the growth of the yeast population in all rooms, despite the 16-18\% lower Saccharomyces contamination in the control room (Figure 5). Moghaddam et al. (2013), who compared the percentage inhibition of mycelial growth of different fungi by peppermint oil, reported different tolerance to the oil among fungi, and attributed this effect to the higher production of enzymes that catalyze oxidation, and therefore, inactivate the added oil. Inhibition of the growth of fungal pathogens may be caused by emulsion damage of the cell wall and cell membrane to various degrees due to different capacities of the oil to penetrate the chitin-based cell walls of fungal hyphae (Moghaddam et al., 2013). Tampieri et al. (2005) indicate that the analysis of the chemical structures seems to suggest that the activity of the oils may depend upon both the presence of the aromatic ring and the presence of the free phenol hydroxyl group. Some authors (Hammer et al., 1999; Kędzia \& Hołderna-Kędzia, 2007), who investigated the in-vitro activity of over 50 different plant oils and extracts against microorganisms, report that thyme oil was the most effective against Saccharomyces fungi. Peppermint oil in their studies was efficient at high concentrations. Yang and Clausen (2007) reported that thyme oil was efficient against Trichoderma, Penicillium, and Aspergillus species for wood protection. The use of essential oils to improve hygiene standards in poultry houses was investigated by Bakutis et al. (2011), who reported fungal count reduction (17-28\%) after spraying a combination of pine and eucalyptus oil. Mituniewicz et al. (2008) applied the commercial additive Profistreu ${ }^{\circledR}$ (containing organic and inorganic substances and essential oils) to the litter, reported that the count of air fungi was about $0.26 \log _{10}$ CFU/g lower in comparison with the control house. The results of the above-mentioned studies also show the antibacterial effect of essential oils both invitro and in-vivo. It should be added that the fogging of poultry rooms with thyme and peppermint essential oil solutions was effective in reducing bacteria, including coliform bacteria and staphylococci (Witkowska \& Sowińska, 2013).

These promising results show that misting poultry houses with essential oils could be an effective prevention method against fungal aerosol in broiler houses. Stationary mist-fog systems or portable foggers, which are used in poultry buildings to different purposes, could be easily used for essential oil application. Aqueous solution of $100 \%$ natural peppermint oil or thyme oil in concentration from 1:500 (chicks) to $1: 250$ may be misted every few days. However, further investigations are needed to determine the synergistic effects of different oils and their compounds, as well as the best possible doses and methods of application in the field.

\section{REFERENCES}

Arné $P$, Thierry S, Wang D, Deville M, Le Loc'h G, Desoutter A, et al. Aspergillus fumigatus in poultry. International Journal of Microbiology 2011; doi:10.1155/2011/746356.

Azaz AD, Irtem HA, Kurkcuoğlu M, Baser KHC. Composition and the in vitro antimicrobial activities of the essential oils of some Thymus species. Zeitschrift für Naturforschung C 2004;59:75-80.

Bakutis B, Baliukoniene V, Mickiene R. The use of essential oils to improve of environment quality in poultry houses. Proceedings of 15th International Society for Animal Hygiene Congress; 2011; Vienna. Austria. p. 643-645

Chuang PH, Lee CW, Chou JY, Murugan M, Shieh BJ, Chen HM. Antifungal activity of crude extracts and essential oil of Moringa oleifera Lam. Bioresource Technology 2007;98:232-236.

Dhama K, Chakraborty S, Verma AK, Tiwari R, Barathidasan R, Kumar $A$, et al. Fungal/mycotic diseases of poultry-diagnosis, treatment and control:a review. Pakistan Journal of Biological Sciences 2013;16:16261640.

Dutkiewicz J, Pomorski ZJH, Sitkowska J, Krysińska-Traczyk E, Skórska C, Prażmo $\mathrm{Z}$, et al. Airborne microorganisms and endotoxin in animal house. Grana 1994;33:85.

EU Council. EU Council Directive 2007/43/EC of 28 June 2007 laying down minimum rules for the protection of chickens kept for meat production. Official Journal of the European Communities L182/19;12.7.2007; Brussels. Belgium. p. 19-28. 
Witkowska D, Sowińska J, Żebrowska JP, Mituniewicz E
The Antifungal Properties of Peppermint and Thyme Essential Oils Misted in Broiler Houses
Gigli ACS, Baracho MS, Naas IA, Silva RA, Zago R, Dall'Anese FP. Diagnosis and evaluation of fungi presence in the air of two different ventilation systems for broiler houses. Brazilian Journal of Poultry Science 2005; 7:205-208.

Hammer KA, Carson CF, Riley TV. Antimicrobial activity of essential oils and other plant extracts. Journal of Applied Microbiology 1999;86:985990.

Inouye S, Abe S, Yamaguchi H, Asakura M. Comparative study of antimicrobial and cytotoxic effects of selected essential oils by gaseous and solution contacts. International Journal of Aromatherapy 2003;13:33-41.

Iscan G, Kirimer N, Kurkcuoglu M, Baser KH, Demirci F. Antimicrobial screening of Mentha piperita essential oils. Journal of Agricultural and Food Chemistry 2002;50:3943-3946.

Karwowska E. Microbiological air contamination in farming environment. Polish Journal of Environmental Studies 2005;14:445-449.

Katooli N, Maghsodlo R, Honari H, Razavi SE. Fungistatic activity of essential oil of thyme and eucalyptus against of postharvest and soilborne plant pathogenic fungi. Global Journal of Medicinal Plant Research 2012;1:1-4.

Kędzia B, Hołderna-Kędzia E. Studies on effect of volatile oils on pathogenic bacteria, yeast fungi and dermatophytes. Postępy Fitoterapii 2007;2:7177.

Klarić MS, Kosalec I, Mastelić J, Piecková E, Pepeljnak S. Antifungal activity of thyme (Thymus vulgaris L.) essential oil and thymol against moulds from damp dwellings. Letters in Applied Microbiology 2007;44:36-42.

Krnjaja V, Stojanović L, Cmiljanić R, Trenkovski S, Tomašević $D$. The presence of potentially toxigenic fungi in poultry feed. Biotechnology Animal Husbandry 2008;24:87-93.

Litvinov MA. Microscopic soil fungi key. Leningrad: Russia Science Press; 1967.

Lonc E, Plewa K. Microbiological air contamination in poultry houses. Polish Journal of Environmental Studies 2010;19:15-19.

Mituniewicz T, Sowińska J, Wójcik A, Iwańczuk-Czernik K, Witkowska $D$, Banaś J. Effect of disinfectants on physicochemical parameters of litter, microbiological quality of poultry house air, health status and performance of broiler chickens. Polish Journal of Environmental Studies 2008;17:745-750.

Moghaddam M, Pourbaige M, Tabar HK, Farhadi N, Hosseinie SMA. Composition and antifungal activity of peppermint (Mentha piperita) essential oil from Iran. Journal of Essential Oil Bearing Plants 2013;16:506-512.

Moghtader M. In vitro antifungal effects of the essential oil of Mentha piperita L. and its comparison with synthetic menthol on Aspergillus niger. African Journal of Plant Science 2013;7:521-527.

Nardoni S, Mancianti F, Sgorbini M, Taccini F, Corazza M. Identification and seasonal distribution of airborne fungi in three horse stables in Italy. Mycopathologia 2005;160:29.

Nichita I, Tirziu E. Investigations on airborne fungi in poultry houses. Lucrări Stiintifice Medicină Veterinară 2008;41:932-935

Okiki PA, Ogbimi AO. Micro-fungi and mycotoxins in poultry dust. Estudos de Biologia 2011;32/33:81-86.

Omran SM, Esmailzadeh S. Comparison of anti-Candida activity of thyme, pennyroyal, and lemon essential oils versus antifungal drugs against Candida species. Jundishapur Journal of Microbiology 2009;2:53-60.
Pinto E, Vale-Silva L, Cavaleiro C, Salgueiro L. Antifungal activity of the clove essential oil from Syzygium aromaticum on Candida, Aspergillus and dermatophyte species. Journal of Medical Microbiology 2009;58:14541462.

Piontek M. Mould fungi. Zielona Góra: University of Technology Press; 1999.

PN-EN ISO/IEC 17025:2005. General requirements for the competence of testing and calibration laboratories. Warsaw: Polish Committee for Standardization; 2005.

PN-ISO 18593:2005. Food and animal feeding stuffs microbiology. Horizontal methods of sampling from the surface using contact plates and swabs. Warsaw: Polish Committee for Standardization; 2005.

PN-ISO 21527-1:2009. Food and animal feeding stuffs microbiology. Horizontal method of yeasts and molds detection and enumeration Part 1: The method of colony counting in products with water activity higher than 0.95. Warsaw: Polish Committee for Standardization; 2005.

Riccioni L, Orzali L. Activity of tea tree (Melaleuca alternifolia, Cheel) and thyme (Thymus vulgaris, Linnaeus) essential oils against some pathogenic seed borne fungi. Journal of Essential Oil Research 2011;23:43-48.

Rusenova N, Parvanov P. Antimicrobial activities of twelve essential oils against microorganisms of veterinary importance. Trakia Journal of Sciences 2009;7:37-43.

Russel S, Paluchowska-Święcka O. The influence of temperature on fungi concentration in agriculture buildings. Ekologia i Technika 2008;16:150-155

Sawale GK, Roshini S, Tirpude NV, Patil G, Satale SB, Yadav M, et al. Systemic mycosis in commercial broiler chicken flock. Indian Journal of Veterinary Pathology 2012;36:57-59.

Seedorf J, Hartung J, Schroder M, Linkert KH, Phillips VR, Holden MR, et al. Concentrations and emissions of airborne endotoxins and microorganisms in livestock buildings in Northern Europe. Journal of Agricultural Engineering Research 1998;70:97-109.

Shanmugavelu S, Burnett G, Michie W. Effect of misting on the performance of male broilers in an enclosed environment. Journal of Tropical Agriculture and Food Science 2000;28:221-234.

Sowiak M, Bródka K, Kozajda A, Buczyńska A, Szadkowska-Stańczyk I. Fungal aerosol in the process of poultry breeding - quantitative and qualitative analysis. Medycyna Pracy 2012;62:1-10.

Tampieri MP, Galuppi R, Macchioni F, Carelle MS, Falcioni L, Cioni PL, et al. The inhibition of Candida albicans by selected essential oils and their major components. Mycopathologia 2005;159:339-345.

Tymczyna L, Chmielowiec-Korzeniowska A, Drabik A. The effectiveness of various biofiltration substrates in removing bacteria, endotoxins and dust from ventilation system exhaust from a chicken hatchery. Poultry Science 2007;86:2095-2100.

Vermeulen B, De Backer P, Remon JP. Drug administration to poultry. Advanced Drug Delivery Reviews 2002;54:795-803.

Vučemilo M, Matković K, Vinković B, Jakšić S, Granić K, Mas N. The effect of animal age on air pollutant concentration in a broiler house. Czech Journal of Animal Sciences 2007;52:170-174.

Wang Y, Chai T, Lu G, Quan C, Duan H, Yao M, et al. Simultaneous detection of airborne aflatoxin, ochratoxin and zearalenone in a poultry house by immunoaffinity clean-up and high-performance liquid chromatography. Environmental Research 2008;107:139-144. 
Witkowska D, Sowińska J. The effectiveness of peppermint and thyme oil mist in reducing bacterial contamination in broiler houses. Poultry Science 2013;92:2834-2843

Witkowska D, Kwiatkowska-Stenzel A, Jóźwiak A, Choraży L, Wójcik A. Microbiological contamination of air inside and around stable during different seasons of the year. Polish Journal of Environmental Studies 2012;21:1061-1066.

Witkowska D, Szarek J, Iwańczuk-Czernik K, Sowińska J, Mituniewicz T, Wójcik $A$, et al. Effect of disinfecting litter on rearing performance and results of blood indices and internal organs of broiler chickens. Medycyna Weterynaryjna 2007;63:1115-1119.
Witkowska D, Chorąży L, Mituniewicz T, Makowski W. Microbiological contamination of litter and air during rearing of broiler chickens. Woda - Środowisko - Obszary Wiejskie 2010;10:201-210.

Wójcik A, Chorąży L, Mituniewicz T, Witkowska D, Iwańczuk-Czernik K, Sowińska J. Microbial air contamination in poultry houses in the summer and winter. Polish Journal of Environmental Studies 2010;19:10451050 .

Yang VW, Clausen CA. Antifungal effect of essential oils on southern yellow pine. International Biodeterioration \& Biodegradation 2007;59:302306. 
